https://helda.helsinki.fi

\title{
The discursive-material knot : Cyprus in conflict and community media participation
}

\section{Polynczuk-Alenius, Kinga}

2019-02-20

Polynczuk-Alenius , K 2019 , ' The discursive-material knot : Cyprus in conflict and community media participation ' , Information, Communication and Society , vol. 22 , no. 9 , pp. 1347-1348 . https://doi.org/10.1080/1369118X.2019.1576754

http://hdl.handle.net/10138/318084

https://doi.org/10.1080/1369118X.2019.1576754

unspecified

acceptedVersion

Downloaded from Helda, University of Helsinki institutional repository.

This is an electronic reprint of the original article.

This reprint may differ from the original in pagination and typographic detail.

Please cite the original version. 
The discursive-material knot: Cyprus in conflict and community media participation, by Nico Carpentier, New York, Peter Lang, 2017, 472 pp., $£ 45.95$ (epub), ISBN: 978-1-4331-3755-6

\author{
Kinga Polynczuk-Alenius \\ Faculty of Social Sciences \\ Media and Communication Studies \\ P.O. Box 54, Unioninkatu 37 \\ FI-o0014 University of Helsinki, Finland \\ Mobile +358458526337 \\ kinga.polynczuk@helsinki.fi
}

word count: 1,055

Nico Carpentier's book, The discursive-material knot: Cyprus in conflict and community media participation, is an ambitious project that sets out to examine the 'Cyprus problem', and to explore the role of participatory community media in the ongoing process of conflict transformation. Arguably, the most valuable contribution of the volume is its commitment to expanding the field of academic vision, whereby Carpentier attempts to present the issue at hand in all its complexity, seamlessly moving back and forth between the theoretical and empirical planes. To do so, the book is structured as a 'triptych', spanning three, distinct but interconnected, 'platforms' of varied levels of abstraction, descending from ontological level to theoretical framework to ontic level. The originality and panache of Carpentier's endeavour has the potential to embolden the readers of his book to pursue sophisticated research that crosses disciplinary boundaries and, in doing so, couples high theory with meticulous empirical work.

Reversing the structure of the monograph, let us begin with a short overview of the empirical context in which Carpentier's project is set. At the first glance, the peculiar predicament of Cyprus resides in the fact that the island, a member state of the European Union, is partly under military occupation by the 'third-country'. The Turkish invasion of 1974 was, however, a culmination of the long-running tension between two largest populations inhabiting the island: the Greek Cypriot majority and the Turkish Cypriot minority. This tension existed when Cyprus was part of the Ottoman Empire, continued during the British rule that followed World War I, shaped the Independence War in 1950s, and escalated into ethnic violence throughout 196os. After the Turkish intervention, forced relocations led to the geographical separation of the two groups, with many people killed or 'disappeared' in the process. Although the memory of conflict is still very much alive, visibly influencing present ethnic relations, the fierce antagonism has slowly begun to transform as a result of the developments that were jointly experienced by both groups, such as the EU accession or the economic crisis. Three platforms of Carpentier's book follow the ongoing process of conflict transformation in Cyprus and, in doing so, take us in an iterative-cyclical manner from the level of high theory 
to the level of deployable analytical framework to the nitty-gritty of empirical analysis.

Platform 1 seeks to connect the discourse theory of Laclau and Mouffe with some new materialist thought so as to construct the ontology of the titular 'knot' that tangles together the 'discursive' and 'material' matter of the world in a nonhierarchical way. This highly theoretical ontology is 'concretised' in Platform 2 in relation to the empirical case at hand. That is, the perspective developed in Platform 1 is deployed in Platform 2 theoretically to re-read a variety of concepts from the fields of participatory theory, community media theory, and conflict (resolution/transformation) theory. Platform 3, in its turn, takes the reader to the ontic/empirical level. It does so in two steps. Firstly, it provides an extensive contextual analysis of the 'Cyprus problem' and re-reads its historical trajectory as a case of (partial) conflict transformation. Finally, the volume engages in a meticulous and critical empirical analysis of the role that community media, with its participatory-democratic dynamics, (might) play in the conflict transformation. This is done through the case study of the Cyprus Community Media Centre (CCMC), a local community media organisation, and its participatory webradio, MYCYradio.

Carpentier's is undoubtedly a valuable contribution and in several ways. As mentioned, the book is, above all, a powerful case for theoretical brevity and conceptual creativity. Carpentier cross-fertilises various disciplines, perspectives and approaches. He pulls elements from several fields of research, moulds them and then uses them to re-read the existing literature. The efficacy of this effort is surely inspiring.

In addition to acting as an original and inspirational model for the readers, Carpentier's endeavour makes also more tangible and immediate contributions. Firstly, this book renders discourse theory more accessible and useful to media and communication scholars. It might indeed be the most extensive work of this kind. Secondly, the book fleshes out the non-hierarchical quality of the relationship between discursive and material dimensions of the social world. It does so in opposition to the analyses which tend to privilege one over the other. Thirdly, the wealth of literature that the author brings into the productive dialogue is highly impressive. So is the polyvocality of this literature, which spans international, particularly theoretical, literature as well as research conducted by local scholars. On a more empirical-perhaps even normative-plane, Carpentier's innovative use of the concepts of 'agonism' and 'conflict transformation' identifies and amplifies the potential for social change in the Cypriot context.

Inevitably, even despite the book's length, there are some blindspots. I would like to point to two threads that would perhaps merit a more extensive treatment. Firstly, the question of epistemological implications of the proposed ontology is never posed. A more explicit reflection on the author's positionality would be valuable, particularly given Carpentier's declared proclivity towards 'rich description' and the epistemological implications of the social constructionist paradigm he adopts.

Secondly, and perhaps more fundamentally, while it is theoretically clear that the ontology of discursive-material knot is a non-hierarchical one, the empirical analysis 
still seems to privilege the discursive component. While Carpentier acknowledges early on that '[o]ne component always has to come first, but this is done without ever implying that their relationship is hierarchical' (p. 4), this does not suffice to explain away the imbalance in Platform 3 between the discursive and material aspects. Perhaps it is so that the case of the CCMC and MYCYradio is, in the last instance, not quite as profound as the theoretical arsenal deployed to analyse it, leaving the material component of the discursive-material knot underused.

Having said that, Carpentier's volume is definitely worthwhile as an introduction to the 'Cyprus problem', as a study of community media, as a guidebook for media and communication scholars wanting to explore the potential of discourse theory, andmost importantly-as a model for novel, ambitious and rich research projects. 